\title{
Do Korean Medical Schools Provide Adequate End-of-Life Care Education? A Nationwide Survey of the Republic of Korea's End-of-Life Care Curricula
}

\author{
Kyong-Jee Kim, Ph.D., Do Yeun Kim, M.D., Ph.D.*, Sung Joon Shin, M.D., Ph.D.*, \\ Dae Seog Heo, M.D., Ph.D. ${ }^{\dagger}$ and Eun Mi Nam, M.D., Ph.D. ${ }^{\ddagger}$
}

Department of Medical Education, Dongguk University School of Medicine, *Department of Internal Medicine, Dongguk University School of Medicine, Goyang, ${ }^{\dagger}$ Department of Internal Medicine, Seoul National University Hospital, ${ }^{\ddagger}$ Department of Internal Medicine, Ewha Womans University College of Medicine, Seoul, Korea

Purpose: Physician competency in end-of-life (EOL) care is becoming increasingly important. This study investigated the EOL care curricula in Korean medical schools. Methods: Questionnaires were issued to the faculty members responsible for the EOL care curricula at each of the medical schools. These included questions on the structure and content of the curricula, teaching methods, and faculty members' attitudes to the curricula. Results: Characteristics of the EOL care curricula were compiled from 27 (66\%) of the 41 medical schools. All of the medical schools taught essential aspects of the EOL care curriculum either as a separate course or embedded within other medical education courses. The mean time spent on EOL care teaching was $10 \mathrm{hrs}$ (range, 2 32 hrs). The most frequently taught topics were delivering bad news (100\%) and symptom management (74\%). When the palliative care education assessment tool (PEAT) was used to evaluate the curricula, a median of 11 PEAT objectives was met (range, 2 26; maximum, 83). More than two teaching methods were used in most of the curricula. However, lectures were the only teaching method used by three medical schools. $78 \%$ of faculty members who were responsible for curriculum reported dissatisfaction with it, whereas $18 \%$ believed that the time allotted to it was adequate. Only $7 \%$ of these faculty members believed that their students were adequately prepared to practice EOL care. Conclusion: There is a need to improve EOL care education in basic medical curricula and to take a more systematic approach to achieving learning outcomes.

Key Words: Curriculum, Hospice care, Palliative care, Teaching, Terminal care
Received September 5, 2019

Revised November 27, 2019

Accepted November 27, 2019

\section{Correspondence to \\ Eun Mi Nam \\ Department of Internal Medicine, Ewha Womans University College of Medicine, 25 Magokdong-ro 2-gil, Gangseo-gu, Seoul 07804, Korea \\ Tel: +82-2-6986-1640 \\ Fax: +82-2-6986-3239 \\ E-mail:enam34@ewha.ac.kr}

\section{The first two authors contributed} equally to this work.

This research was supported by the Korean Society for Hospice and Palliative Care.

\section{INTRODUCTION}

Physician competency in end-of-life (EOL) care is becoming increasingly important due to an increase in life expectancy and advances in medical technology. Medical students with more exposure to EOL care have more positive attitudes toward and feel better prepared to provide such care require that EOL care is taught as part of the core medical education curriculum (1-4). Consequently, medical schools in the United States and Europe have included EOL care in their basic medical education curricula (5-8). Furthermore, a study of final-year medical students in Britain and the United States 
showed that the majority recognized the importance of EOL care education (9). Nevertheless, some studies have reported concerns about the quality of EOL care curricula. A survey of medical students graduating in the United States found that the quality of EOL care education was inadequate. In total, $53 \%$ of these students reported learning little or nothing about palliative care from attending non-palliative care classes, and $78 \%$ of the students reported learning only a limited amount from residents (10). In addition, Schmit et al (11) reported that residents and fellows considered the EOL care communication skills education they received during medical school and residency to be insufficient. However, there has been significant progress in EOL care education recently. Fitzpatrick et al (12) showed that medical schools took various approaches to teaching this subject from a review of international studies on palliative care education.

Across the world, the need for core EOL care learning objectives, more opportunities for patient and family contact, mandatary hospice experience, expert panels to develop curricula, and a diverse range of teaching methods, such as role play, have been recognized (13).

In addition, it is obvious that there is a growing need for education and training in EOL care for medical students and physicians in the Republic of Korea, particularly since legislation acknowledging that patients can refuse life-sustaining treatment came into force in February 2018.

However, information on the quality and characteristics of EOL care education available to undergraduate medical students in Korea is limited. A recent study of interns at Korean academic medical centers suggested that the EOL care education they had received in their basic medical education programs was inadequate (14). Therefore, there is a pressing need for research to investigate the current status of EOL care curricula within Korean medical schools to determine whether these curricula are adequate to develop the required EOL care competencies.

This study examined the status of the EOL care curricula in medical schools within the Republic of Korea to determine whether these curricula are providing adequate preparation for medical students to practice in the future.

\section{METHODS}

\section{Survey instrument}

A questionnaire was developed and implemented to evaluate the EOL care curricula at medical schools across the nation. The questionnaire assessed characteristics of the EOL care curricula and each faculty's satisfaction with their own EOL care curriculum.

The questionnaire included three parts. The first part included three items and asked whether EOL care education was provided as a separate course or embedded within other courses. If the faculty did not have a separate EOL care course, they were asked whether they planned to offer such a course in the future. The second part of the questionnaire collected information about the general characteristics of the EOL care curriculum. The respondents listed the EOL care topics covered by their curriculum as well as the instruction time, objectives, and the year of study in which each topic is taught. Respondents were also asked to indicate the teaching methods used by choosing from lectures, various classroom activities (e.g., small-group discussions, role play, videos), and clinical clerkships. The final part of the questionnaire asked respondents who were responsible for the faculty for their opinion of the EOL care curriculum. There were four items graded using a five-point Likert scale, where $1=$ "strongly disagree" and 5= "strongly agree". The Cronbach's alpha score for faculty attitudes toward their EOL care curricula was 0.76, indicating reliable internal consistency.

The questionnaire was based on a research instrument used to evaluate undergraduate palliative medicine education in Canada (15). The researchers who are experts on the EOL care or have experience in curricular development designed the contents of this survey. The three researchers have an experience over 10 years in EOL care for cancer patients and published many articles about hospice and palliative care. Another one researcher has interested in critical care of clinical nephrology and developing a new curriculum that can tackle current ethical challenges. And last one researcher has published in a broad range of areas in medical education including; curriculum design, evaluation, and e-learning. It was developed after several rounds of feedback among researchers. 
The survey is shown in Appendix 1.

\section{Data collection}

The questionnaires were sent by $\mathrm{e}^{-}$mail to the course directors or faculty members teaching EOL care curriculum subjects in all medical schools in the Republic of Korea (a total of 41 at the time of the study) between March and May, 2016. The questionnaires were accompanied by requests to participate from the Korean Association of Medical Colleges and the Korean Society for Hospice and Palliative Care. The instrument was self-administered and questionnaires were returned by $\mathrm{e}^{-}$ mail or by post in a sealed envelope. A follow-up $\mathrm{e}^{-}$-mail was sent to non-responders to remind them to participate.

\section{Data analyses}

Categorical data are presented using descriptive statistics. We used the palliative care education assessment tool (PEAT) to evaluate data for the objectives in each curricular domain, in accordance with the method described by Schiessl et al (13). The PEAT comprises seven domains and 83 objectives (16). The domains include palliative medicine (6 objectives), pain (12 objectives), neuropsychological syndromes (11 objectives), other symptoms (10 objectives), ethics and the law (20 objectives), patient/family/caregiver nonclinical perspectives on EOL care (12 objectives), and clinical communication skills (12 objectives). Independent $\mathrm{t}$-tests were used to compare respondents' attitudes toward EOL care education across different curricular formats. Correlational analyses were performed to analyze associations between EOL care curricula formats and faculty perceptions of curricula using the Pearson correlation coefficient. The data were analyzed using SPSS software (ver. 22.0; IBM, Armonk, NY, USA) and a P-value <0.05 was considered statistically significant.

\section{Ethical considerations}

This study was reviewed and approved by the Institutional Review Board of Dongguk University Hospital (Goyang, Republic of Korea; IRB No:2-16-13). Participation was voluntary, and respondents completed their questionnaires privately and anonymously.

\section{RESULTS}

\section{Structure and instruction times for EOL care curricula}

In total, 27 of the 41 medical schools in the country responded to the survey (66\% response rate). Seven (26\%) provided a separate course in EOL care, whereas the remaining 20 taught the topic as part of other courses (Table 1).

Among schools that did not have a separate course in EOL care, $5(19 \%)$ responded they planned to offer it in a separate course format, while 15 (56\%) answered they felt the need to develop as a separate course. Those responded that there was no need to offer EOL care education as a separate course pointed out that the relevant learning outcomes were being covered in the existing courses.

The EOL care instruction time within basic medical education curricula varied across schools, ranging from 2 to $32 \mathrm{hrs}$ (mean, 10.22 hrs; standard deviation, 6.28 hrs) (Table 1). Most medical schools provided EOL care instruction across the preclinical (years 1 2) to the clinical (years 3 4) stage. In the preclinical phase, the emphasis was on communication, attitudes, ethics, and an introduction to EOL care, whereas during the clinical years, the emphasis was on practical management and clinical experience.

\section{EOL care curricula content}

The most frequently taught topics were delivering bad news (27 schools, 100\%), symptom management (20 schools, 74\%), and physician assisted suicide/euthanasia (18 schools, 67\%).

Among the 27 curricula, data from 20 medical schools could

Table 1. Structure and Instruction Times for EOL Care Curricula.

\begin{tabular}{lc}
\hline \multicolumn{1}{c}{ Characteristics } & $\mathrm{n}(\%)$ \\
\hline Schools responding to survey & $27(66)$ \\
Course format* & \\
Separate & $7(26)$ \\
Integrated & $20(74)$ \\
EOL care instruction time (hrs, M \pm SD) & $10.22 \pm 6.28$ \\
\hline
\end{tabular}

*The integrated course format means EOL care is taught as part of other courses; the separate course format is when the course in EOL care is offered not being integrated into other courses.

EOL: End-of-Life. 
be evaluated using the PEAT. The number of specific objectives per domain varied for each medical school (median, 11 objectives; range, 2 26). Table 2 shows the medical schools teaching at least one objective from each domain.

When the results are separated according to domains, communication skills with patients and families, such as breaking bad news and/or advance directives were common among the 12 objectives of domain VII (Figure 1). Most of the objectives from domain II (pain) were met by 5 14 medical schools. The most frequently taught objectives from domain $\mathrm{V}$ (ethics and law) concerned the definition of physician-assisted suicide and voluntary active euthanasia (8/20 medical schools, 40\%) and the legal and ethical basis of do not resuscitate decisions $(6 / 20$ medical schools, 30\%). Objectives such as truth telling (domain $\mathrm{V}$ ), community resources and social support, suffering (domain VI), and interdisciplinary care teams (domain VII) were each met at only one medical school. Several objectives were not taught by any of the 20 medical schools, including clinical capacity determination and legal concepts, futility (domain V), and suicidality (domain VI).

\section{Educational methods used in EOL care curricula}

Table 3 shows the teaching methods used in EOL care curricula. Lectures accounted for $73 \%$ of the total instruction time and were used in all of the medical schools. Three medical schools teaching EOL care (11\%) used lectures only. Most medical schools used lectures combined with small-group dis- cussions, clinical clerkships, role play, or videos. Nine medical schools teaching EOL care (33\%) used lectures, active learning methods in the classroom, and clinical clerkships. One medical school included case discussions of hospice cancer patients. This school offered one-week course called 'end of life care' to medical students in their fourth year. Delivering bad news was the most popular topic for active learning, such as small-group discussions or role play. Sometimes, standardized patients and role play were used teach students how to deliver bad news. Videos were also used to learn about death, advanced care planning, condolence, and communication techniques.

\section{Faculty members' attitudes toward their EOL care curricula}

Table 4 lists descriptive statistics for faculty members' attitudes toward their EOL care curricula. Only 22\% (n=6) of respondents were satisfied with their EOL care curricula and $19 \%(n=5)$ believed that the instruction time allotted to EOL care in their curricula was adequate. In total, $59 \%(n=16)$ of respondents reported that their students gained sufficient EOL care experience during their clinical rotations. However, only $7 \%(n=2)$ of respondents agreed that their students were adequately prepared to practice EOL clinical care.

Faculty members' overall attitudes toward their EOL care curricula were similar, regardless of whether EOL care was taught as a separate course or as part of integrated medical training $(\mathrm{t}=0.36, \mathrm{P}=0.72)$. Attitudes toward EOL care cur-

Table 2. Presence of at Least Objectives Being Taught Classified by the Curricular Domain of the Palliative Education Assessment Tool (N=20).

\begin{tabular}{|c|c|c|}
\hline Domain & Description & Frequencies (\%) \\
\hline I. Palliative medicine (6 objectives) & Identify the basic concepts of palliative care and its inclusion within the care continuum & $5(83)$ \\
\hline II. Pain (12 objectives) & $\begin{array}{l}\text { Understand the origin of pain and the diagnostic and therapeutic therapies used (e,g,.. as } \\
\text { distinct from suffering and psychosocial stress) }\end{array}$ & $11(92)$ \\
\hline $\begin{array}{l}\text { III. Neuropsychological symptoms } \\
\text { (11 objectives) }\end{array}$ & $\begin{array}{l}\text { Address those symptoms associated with dying, including those that are byproducts of } \\
\text { disease or medications (i.e, agitation, depression, delirium, dementia, etc.) }\end{array}$ & $3(27)$ \\
\hline IV. Other symptoms (10 objectives) & $\begin{array}{l}\text { Address those symptoms that are often the most concern to the patient- those symptoms } \\
\text { that are byproducts of medications (i.e.., dyspnea, nausea/vomiting, constipation, } \\
\text { diarrhea, pruritus, etc.) }\end{array}$ & $6(60)$ \\
\hline V. Ethics and law (20 objectives) & Discuss the ethical and legal issues surrounding the end-of-life & $15(75)$ \\
\hline $\begin{array}{l}\text { VI. Patient/family/caregiver nonclinical } \\
\text { perspectives on end of life care } \\
\text { (12 objectives) }\end{array}$ & Include the concerns of the patient, family, and nonclinical caregiver as the end-of-life is near & $7(58)$ \\
\hline $\begin{array}{l}\text { VII. Clinical communication skills } \\
\text { (12 objectives) }\end{array}$ & $\begin{array}{l}\text { Include clinical communication skills that are essential in all aspects of medicine, and those } \\
\text { skills specific to end-of-life care }\end{array}$ & $12(100)$ \\
\hline
\end{tabular}




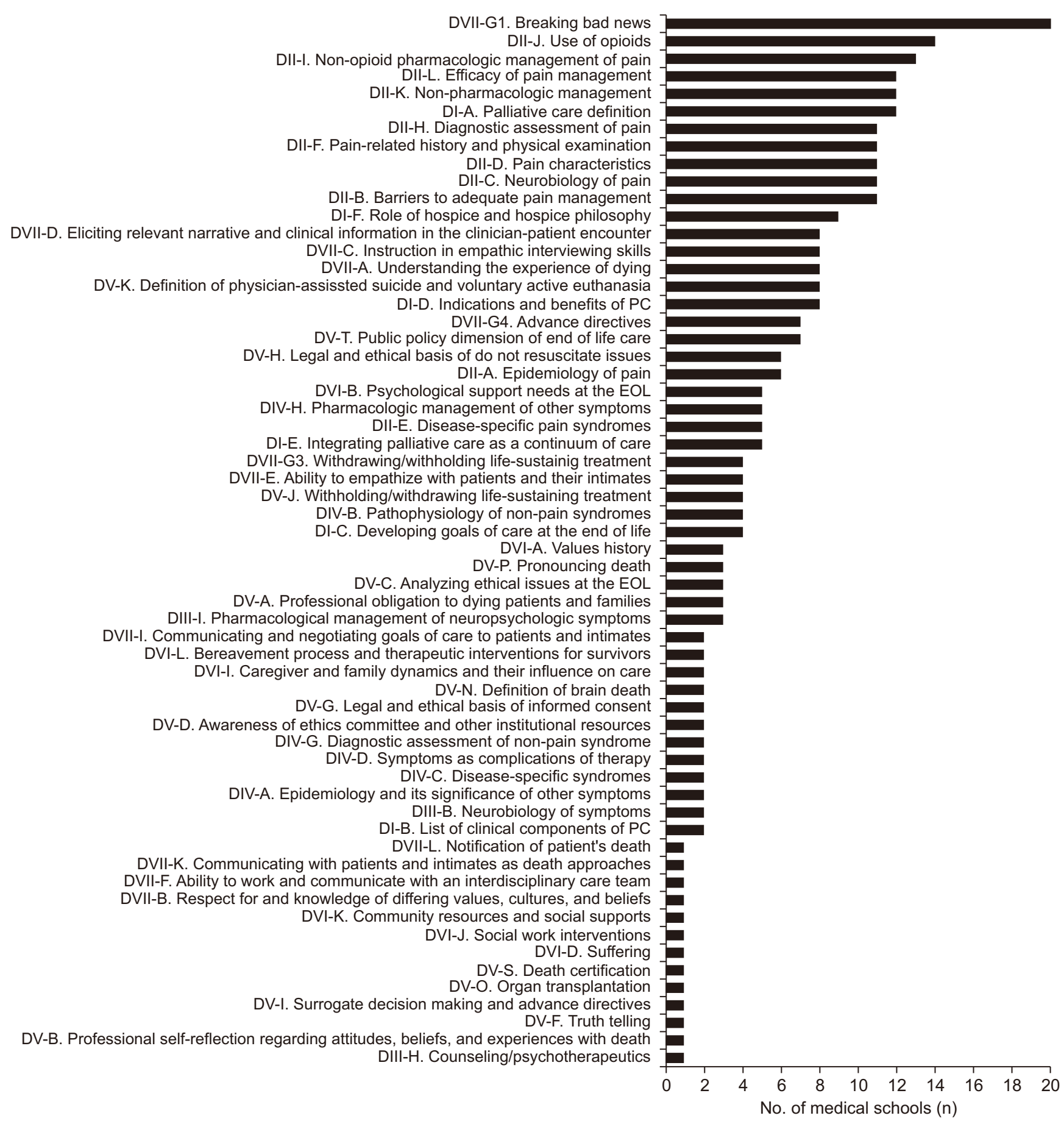

Figure 1. Number of medical schools which offer PEAT objectives ( $N=20)$.

PEAT: palliative care education assessment tool.

ricula were also compared, based on the length of EOL care instruction time. Faculty members had a more positive overall perception of their EOL care curricula when the EOL care instruction times were longer $(\mathrm{t}=2.31, \mathrm{P}<0.05)$ (Table 5).

\section{DISCUSSION}

This is the first study to investigate the EOL care curricula of undergraduate medical schools in the Republic of Korea. As with similar studies performed in Europe and North America (5-9), we found that EOL care education does form part of 
the basic medical education curriculum in Korean medical schools. However, there was significant variation in course formats, content, instruction time, and teaching methods across the different medical schools. Moreover, the faculties involved in teaching EOL care were generally dissatisfied with their curricula.

First, the instruction times allocated to EOL care by medical schools (mean, 10 hrs) were shorter than those reported in the United States and in several European Union nations (13). Medical schools in the United States typically teach EOL care

Table 3. Teaching Methods in EOL Care Curricula ( $N=27)$.

\begin{tabular}{ll}
\hline \multicolumn{1}{c}{ Methods } & $\mathrm{n}(\%)$ \\
\hline Lectures & $27(100 \%)$ \\
Small group learning & $14(52 \%)$ \\
Clinical clerkship* & $12(44 \%)$ \\
Role play & $4(15 \%)$ \\
Videos & $2(7 \%)$ \\
Case discussion & $1(4 \%)$ \\
\hline
\end{tabular}

*Bed side teaching while clinical rotation period.

EOL: End-of-Life. for 4 weeks, whereas European medical schools, such as those in England and Germany, provide approximately $40 \mathrm{hrs}$ (and a minimum of $20 \mathrm{hrs}$ ) of EOL care education at appropriate intervals within the basic medical education syllabus (13). Although there is wide variation in undergraduate EOL care curricula internationally, limited time has been allocated to EOL care education in the Republic of Korea and this varies significantly across medical schools (2 36 hrs). In addition, because there is a lot of medical coursework to teach, it may be impossible to ensure that enough time is spent on EOL care education unless it is made compulsory. More than half (56\%) of the faculty members who responded to our survey said that their EOL care curricula need further development. Therefore, institutional or national support for compulsory EOL care education may be necessary. Boland et al (17) suggested that making EOL care courses compulsory could be the first step in effectively integrating EOL care across the undergraduate curriculum to improve the teaching of palliative care.

We found that communication skills and pain management were the most widely covered topics among the EOL care

Table 4. Faculty Members' Attitudes toward the EOL Care Curricula ( $N=27)$.

\begin{tabular}{|c|c|c|c|c|c|}
\hline Item & Strongly disagree & Disagree & Neutral & Agree & Strongly agree \\
\hline Satisfied with the EOL care curricula & $3(11 \%)$ & $13(48 \%)$ & $5(19 \%)$ & $6(22 \%)$ & $0(0 \%)$ \\
\hline Instruction time on EOL care is adequate & $4(15 \%)$ & $12(44 \%)$ & $6(22 \%)$ & $4(15 \%)$ & $1(4 \%)$ \\
\hline Students spend enough time in EOL care during clinical rotations & $4(15 \%)$ & $3(11 \%)$ & $4(15 \%)$ & $16(59 \%)$ & $0(0 \%)$ \\
\hline Students are prepared for clinical practice in EOL care & $6(22 \%)$ & $16(59 \%)$ & $3(11 \%)$ & $2(7 \%)$ & $0(0 \%)$ \\
\hline
\end{tabular}

EOL: End-of-Life.

Table 5. Faculty Members' Attitudes toward the EOL Care Curricula across Different Course Structure and Format ( $N=27)$.

\begin{tabular}{|c|c|c|c|c|c|c|c|c|}
\hline \multirow{2}{*}{ Item } & \multicolumn{4}{|c|}{$\begin{array}{l}\text { Course format* } \\
\qquad(\mathrm{M} \pm \mathrm{SD})\end{array}$} & \multicolumn{4}{|c|}{$\begin{array}{l}\text { Length of instruction time } \\
\qquad(\mathrm{M} \pm \mathrm{SD})^{\dagger}\end{array}$} \\
\hline & $\begin{array}{c}\text { Separate } \\
(\mathrm{n}=7)\end{array}$ & $\begin{array}{l}\text { Integrated } \\
(\mathrm{n}=20)\end{array}$ & $\mathrm{t}$ & P-value & $\begin{array}{l}\leq 10 \mathrm{hrs} \\
(\mathrm{n}=11)\end{array}$ & $\begin{array}{l}>10 \mathrm{hrs} \\
(\mathrm{n}=14)\end{array}$ & $\mathrm{t}$ & P-value \\
\hline Satisfied with the EOL care curricula & $2.40(0.940)$ & $2.86(1.069)$ & 1.070 & 0.341 & $2.18(0.982)$ & $2.86(0.949)$ & 1.740 & 0.095 \\
\hline Instruction time on EOL care is adequate & $2.40(0.940)$ & $2.71(1.380)$ & 0.673 & 0.507 & $2.18(1.250)$ & $2.79(0.893)$ & 1.410 & 0.172 \\
\hline $\begin{array}{l}\text { Students spend enough time in EOL care during } \\
\text { clinical rotations }\end{array}$ & $3.25(1.251)$ & $3.00(0.816)$ & 0.490 & 0.628 & $2.73(1.421)$ & $3.57(0.852)$ & 1.847 & 0.078 \\
\hline Students are prepared for clinical practice in EOL care & $2.05(0.887)$ & $2.00(0.577)$ & 0.138 & 0.891 & $1.73(0.647)$ & $2.36(0.842)$ & 2.048 & 0.052 \\
\hline Total & $2.52(0.794)$ & $2.64(0.720)$ & 0.3 & 0.72 & $2.20(0.820)$ & $2.89(0.626)$ & 2.31 & 0.026 \\
\hline
\end{tabular}

*The integrated course format means EOL care is taught as part of other courses; the separate course format is when the course in EOL care is offered not being integrated into other courses, ${ }^{\dagger}$ Two missing data.

EOL: End-of-Life. 
curricula $(15,18,19)$. In particular, delivering bad news is an essential topic for the Korean Medical License Examination. All of the medical schools covered this topic, although they used different teaching methods. We compared our curricula objectives in each curricular domain using PEAT with data from a worldwide review of undergraduate EOL care curricula (13). Although 60 of the 83 PEAT objectives were met across the schools considered, a median of only 11 objectives were met. This suggests that these objectives were not consistently covered across the schools and students would not acquire the same set of core competencies. The objectives from domain II (pain) and domain VII (communication skills) were covered most frequently. However, domain III (neuropsychological symptoms) and domain IV (other symptoms) objectives were covered by less than one-quarter of the medical schools. The objectives included in domain V (ethics and the law) were covered by medical schools in our study, reflecting the recent introduction of the Self-determination Act and issues regarding life sustaining treatment for terminally ill patients. Interestingly, the least taught domain was domain VI (patient/familial perspectives), although this was the domain covered by the largest number of international medical schools (13). In addition, although several domain VII objectives were taught, these rarely included multidisciplinary teamwork. EOL care has emotional costs for patients, families, and physicians. Our recent study showed that medical trainees' experiences of death and dying occurred mostly during their final year of medical school. Such experiences may generate powerful emotions. Therefore, discussions about death and dying and thinking about the factors that affect the experience of dying are important steps in accepting the inevitability of death and developing adequate coping strategies (20).

Most of all, our findings suggest that not enough teaching time is currently allocated to meeting the necessary learning objectives for EOL care within the curricula. Therefore, learning objectives and competencies need to be prioritized. As with the PEAT, the Korean Association of Medical Colleges also list several learning outcome requirements for basic medical education, such as delivering bad news, providing a sense of dignity, and understanding the bereavement process (21). However, our results show that these topics are not always covered. Therefore, a more careful approach to teaching $\mathrm{Ko}^{-}$ rean medical students EOL care is needed.

In addition, a shift toward more active learning may enhance our teaching approach. We found that most EOL care instruction time involved lectures, and three Korean medical schools only used lectures as a teaching method. As with other international medical schools, some Korean schools used various teaching methods. However, simulation and role play (15\%) were rarely used compared to international data $(20 \sim 40 \%)$ on palliative care education for undergraduate medical students. Similarly, online/technology was rarely used in our study $(<10 \%)$ compared to medical schools in the UK (up to 79\%) (12). Moreover, teaching activities such as reflective essays and hospice visits were not mentioned by any of the Korean medical schools. Hospice visits are considered mandatory for EOL care education and many international medical schools include these, including up to $92 \%$ of UK medical schools $(12,17,20)$. These findings suggest that a greater number of diverse and active learning approaches should be used to improve EOL care education in Korean medical schools. The neglected domain IV objectives and absent teaching methods, such as reflective essays and hospice visits, suggest that EOL care education in the Republic of Korea should focus more on the patient's value and relieving suffering.

As of 2019, the Korean Society for Hospice and Palliative Care certifies physicians for hospice and palliative medicine (22). However, the tutors involved in our analyses specialized in hematology, medical oncology, medical ethics, family medicine, and psychiatry. In the future, tutors with the necessary certification will be available and palliative medicine will be recognized at a national level.

Most faculty members who responded to our questionnaire and were responsible for an EOL care curriculum were not satisfied with their own curriculum. Fortunately, faculty members' perceptions of their EOL care curriculum were influenced by their students' exposure to EOL care education. This finding is consistent with a study of medical students in the United States, which showed that students felt better prepared to deliver EOL care and rated their EOL care curricula more highly when they had more exposure to EOL care education (1).

This study had some limitations. First, approximately onethird of the medical schools did not respond to the survey, and only about half of them could be evaluated using the PEAT. 
Some respondents described curricular objectives (e.g., 'other symptom control, such as dyspnea, delirium') in such a way that they could not be categorized using the PEAT. Although the PEAT is not validated for analyzing curricula from different countries, comparing our results with international data may provide valuable insight. A future study using a checklist to evaluate our curricula and curricular mapping may overcome this limitation. Second, we did not investigate the informal and hidden curricula. Previous studies have shown that the informal and hidden curricula can sometimes impair learning if they convey negative messages (1,23-25). Therefore, a future study of the three EOL care curricula modalities is needed to understand the development of EOL care education in depth. Third, we did not investigate how EOL care curricula students are assessed. Because student assessment is fundamental to the quality of educational programs, an evaluation of the student assessment process will also be necessary to identify aspects of the EOL care curriculum that could be improved.

This study highlights the need to improve EOL care education in basic medical curricula within the Republic of Korea. National guidelines or legislation should be introduced to ensure that physicians are adequately equipped to provide EOL care.

\section{요약}

목적: 임상 의사가 생의 말기 '임종 돌봄(end of life care)'에 대한 진
료 역량을 갖추는 것은 점차 중요해 지고 있다. 본 연구는 국내 의과 대학에서 임종 돌봄에 대한 교과과정에 대해 조사하고자 하였다.

방법: 각 의과대학에서 임종 돌봄 교과과정에 책임을 지고 있는 교 수들에게 교과과정에 대한 내용, 강의 시간, 강의 방법과 교과과정에 대한 태도를 설문지를 통해 분석하였다.

결과: 전체 41 개 의과대학 중 27 개 의과대학 $(66 \%)$ 에서 설문에 응하 였다. 모든 의과대학에서 임종 돌봄 교과과정을 단독교과목이나 다 른 교과과정 중 포함시켜 교육하고 있었다. 임종 돌봄을 가르치는 시간의 중앙값은 10시간(2 32 시간 범위)였다. 가장 많이 강의 되 고 있는 주제는 나쁜 소식 전하기(100\%)와 증상 조절(74\%)이였다. 완화의료교육과정 평가 도구(palliative care education assessment tool; PEAT)를 적용하였을 때 11개(범위: 2 26; 최대: 83)의 PEAT 목적이 만족되었다. 교육과정에 대부분 2가지 이상의 교육방법이 사 용되었으나 3 개 의과대학에서는 오직 강의만을 교육방법으로 사용 하고 있었다. 교과과정 책임 교수의 78\%가 교과과정에 대해 만족하 지 않는다고 응답하였고 $18 \%$ 만이 임종 돌봄 강의 시간이 적당하다 고 생각하였다. 단지 $7 \%$ 의 교수만 학생들이 임종 돌봄 관련 실제 진 료를 할 수 있는 역량을 갖췄다고 답했다.

결론: 의과대학 교육과정 내에 임종 돌봄 관련 학습성과가 도출되고 이를 달성하기 위해 교육과정이 체계적으로 운영되어 졸업 후 학생 들이 실제 진료 역량을 갖출 수 있도록 하는 것이 필요할 것으로 생 각된다.

중심단어: 교과과정, 완화의료, 임종 돌봄, 의과대학 교육, 호스피스

\section{REFERENCES}

1. Billings ME, Engelberg R, Curtis JR, Block S, Sullivan AM. Determinants of medical students' perceived preparation to perform end-of-life care, quality of end-of-life care education, and attitudes toward end-of-life care. J Palliat Med 2010;13:319-26.

2. Wechter E, O'Gorman DC, Singh MK, Spanos P, Daly BJ. The effects of an early observational experience on medical students' attitudes toward end-of-life care. Am J Hosp Palliat Care 2015;32:52-60.

3. Tomorrow's doctors: outcomes and standards for undergraduate medical education [Internet]. London: General Medical Council; c2009 [cited 2019 May 30]. Available from http://www.ub.edu/medicina_unitateducaciomedica/documentos/TomorrowsDoctors_2009.pdf.

4. Liaison Committee on Medical Education. Functions and structure of a medical school: standards for accreditation of medical education programs leading to the MD degree. Washington, D.C.:Liaison Committee on Medical Education;2016.

5. Block SD. Medical education in end-of-life care: the status of reform. J Palliat Med 2002;5:243-8.

6. Carrasco JM, Lynch TJ, Garralda E, Woitha K, Elsner F, Filbet M, et al. Palliative care medical education in European universities: a descriptive study and numerical scoring system proposal for assessing educational development. J Pain Symptom Manage 2015;50:516-23.

7. Dickinson GE. A 40-year history of end-of-life offerings in US medical schools: 1975-2015. Am J Hosp Palliat Care 2017;34:559-65.

8. Horowitz R, Gramling R, Quill T. Palliative care education in U.S. medical schools. Med Educ 2014;48:59-66.

9. Hammel JF, Sullivan AM, Block SD, Twycross R. End-of-life and palliative care education for final-year medical students: a comparison of 
Britain and the United States. J Palliat Med 2007;10:1356-66.

10. Head BA, Schapmire TJ, Earnshaw L, Chenault J, Pfeifer M, Sawning S, et al. Improving medical graduates' training in palliative care: advancing education and practice. Adv Med Educ Pract 2016;7:99-113.

11. Schmit JM, Meyer LE, Duff JM, Dai Y, Zou F, Close JL. Perspectives on death and dying: a study of resident comfort with end-of-life care. BMC Med Educ 2016;16:297.

12. Fitzpatrick D, Heah R, Patten S, Ward H. Palliative care in undergraduate medical education-how far have we come? Am J Hosp Palliat Care 2017;34:762-73.

13. SchiessI C, Walshe M, Wildfeuer S, Larkin P, Voltz R, Juenger J. Undergraduate curricula in palliative medicine: a systematic analysis based on the palliative education assessment tool. J Palliat Med 2013;16:20-30.

14. Kim DY, Kim KJ, Shin SJ, Kwon I, Nam EM, Heo DS, et al. The necessity for end-of-life care education: Preliminary analysis with interns at two university hospitals. Korean J Hosp Palliat Care 2017;20:111-21.

15. Oneschuk D, Moloughney B, Jones-McLean E, Challis A. The status of undergraduate palliative medicine education in Canada: a 2001 survey. J Palliat Care 2004;20:32-7.

16. Meekin SA, Klein JE, Fleischman AR, Fins JJ. Development of a palliative education assessment tool for medical student education. Acad Med 2000;75:986-92.

17. Boland JW, Barclay S, Gibbins J. Twelve tips for developing palliative care teaching in an undergraduate curriculum for medical students. Med Teach 2019: 41:1359-65.

18. Gibbins J, McCoubrie R, Maher J, Wee B, Forbes K. Recognizing that it is part and parcel of what they do: teaching palliative care to medical students in the UK. Palliat Med 2010;24:299-305.

19. Shaheen AW, Denton GD, Stratton TD, Hoellein AR, Chretien KC. End-of-life and palliative care curricula in internal medicine clerkships: a report on the presence, value, and design of curricula as rated by clerkship directors. Acad Med 2014;89:1168-73.

20. Jedlicska N, Srnova D, Scheide L, Wijnen-Meijer M, Gartmeier M, Berberat PO. Medical trainees' experiences with dying and death. Omega (Westport). Epub 2019 Apr 16.

21. Korean Association of Medical Colleges. Learning outcomes of basic medical education: Clinical competency-centered. 2nd ed. Seoul:Korean Association of Medical Colleges;2016. p.195.

22. Kim CG. The history of hospice and palliative care in Korea. Korean J Hosp Palliat Care 2019;22:1-7.

23. Fins JJ, Gentilesco BJ, Carver A, Lister P, Acres CA, Payne R, et al. Reflective practice and palliative care education: a clerkship responds to the informal and hidden curricula. Acad Med 2003;78:307-12.

24. Fins JJ, Rodríguez del Pozo P. The hidden and implicit curricula in cultural context: new insights from Doha and New York. Acad Med 2011;86:321-5.

25. Ratanawongsa N, Teherani A, Hauer KE. Third-year medical students' experiences with dying patients during the internal medicine clerkship: a qualitative study of the informal curriculum. Acad Med 2005;80:641-7. 